1. Introdução;

2. Antecedentes:

3. O Plano Austral;

4. Comentários conclusivos.

\section{Avaliação do plano austral - aspectos destacados da agricultura argentina}

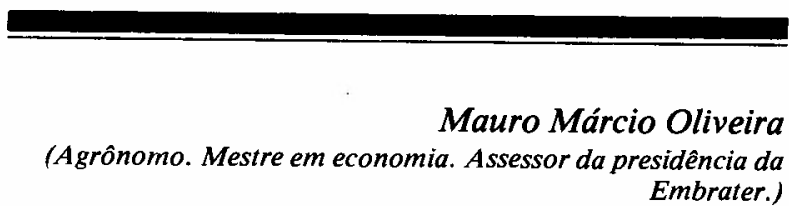

\section{INTRODUÇÃO}

Este trabalho originou-se do interesse em trazer uma contribuição ao acompanhamento do Plano Cruzado através de um estudo da evolução do Plano Austral da Argentina, com algum detalhamento para a situação da agricultura daquele país. Afora as informações contidas na literatura pertinente (citada e consultada), as posições aqui expostas decorrem, em boa proporção, dos contatos e discussões com as pessoas e instituições entrevistadas em maio deste ano, na Argentina:

- Lic. Miguel Paulette - Chefe do escritório local do lica.

- Ing. Andrés Abramovic e Dr. Carlos Garramon, assessores do Secretário de Agricultura, Ganadería y Pesca, Ing. Lucio Reca.

- Ing. Agr. Angel Marzocca, diretor nacional do Instituto Nacional de Tecnologia Agropecuária (Inta).
- Señor Manfredo Von Rennekampff, presidente de Asociación Argentina de Consorcios Regionales de Experimentación Agrícola (AACREA).

- Dr. Evarigelino Gomez, assessor do Secretário de Agricultura, Ganadería y Pesca.

- Ing. Agr. Martín Nauman, diretor nacional de extensão agropecuária do Inta.

- Ing. Agr. Juan Noccetti, do Inta.

- Lic. Alejandro Vegh Villegas, economista-chefe da Sociedad Rural Argentina.

- Ing. Agr. Agustín Segovia Fernández, gerente da Cámara de Productos Fitosanitarios e Fertilizantes.

- Ing. Luis Cuscia, diretor de economia e sociologia rural da Secretaría de Agricultura, Ganadería y Pesca.

Todas as opiniões aqui externadas são de exclusiva responsabilidade do autor, não cabendo ônus de erros e de interpretação às pessoas e instituições mencionadas.

\section{ANTECEDENTES}

\subsection{Aspectos macroeconômicos}

A economia argentina, no período anterior mais recente, esteve mergulhada num ciclo recessivo em virtude de uma série de fatores. A dívida externa elevada - proporcionalmente, a maior do mundo - associada a uma excessiva carga de juros acelerou e aprofundou os sinais de crise. Para tanto contribuiu a fuga de capitais entre os anos de 1980 e 1981. Da mesma forma que no Brasil, a transferência da dívida externa do setor privado para o setor público tornou crítica sua gerência, obrigando o Governo a promover sucessivos ajustes nas tarifas, seguidas emissões e novos empréstimos externos para pagar o serviço da dívida. Como se isso não bastasse, a depressão dos preços internacionais das commodities agrícolas (3/4 da exportação argentina) acabou por inviabilizar o pagamento integral dos serviços como o saldo da balança comercial. A conseqüência destes fatores cumulativos foi a recessão, aumento do déficit fiscal e aceleração inflacionária ao nível de $30 \%$ ao mês, no primeiro semestre de 1985 .

\subsection{Aspectos da agricultura}

O fato mais saliente da história recente da agricultura argentina é o que se pode chamar de "Revolução Pampiana", compreendida entre os anos 1975/76 e 1982/83. Neste período, a produção de grãos cresce $80 \%, 16 \%$ dos quais atribuíveis à ampliação de área. Isso mostra que o vetor fundamental foi a melhoria do padrão tecnológico de exploração. Os elementos dinâmicos que 
concorreram para a configuração deste fenômeno são, de forma sintética:

- exploração da fertilidade natural dos solos;

- melhoramento genético dos grãos;

- introdução da soja;

- propagação das variedades de trigo de ciclo curto (os mexicanos);

- rotação trigo-sója;

- generalização da figura do contratista;

- mercado quase cativo da URSS, durante o embargo americano, por conta da invasão do Afeganistão.

A "Revolução Pampiana" foi levada a cabo na região central da Argentina (províncias de Buenos Aires, Córdoba, Santa Fé), onde a pecuária tem sua zona de máxima exploração. A fertilidade natural dos solos, acrescida da adubação orgânica proporcionada pela exploração da pecuária, foi fundamental para - substituindo pastagens por lavouras de grãos - a obtenção de rendimentos físicos médios de $3.100 \mathrm{~kg} / \mathrm{ha}$ para o sorgo, $3.140 \mathrm{~kg} / \mathrm{ha}$ para o milho, $3.700 \mathrm{~kg} / \mathrm{ha}$ para o arroz, entre outras. $O$ avanço das lavouras, especialmente cereais e oleaginosas, se, em parte, deslocou a pecuária a ponto de provocar a redução do efetivo da pecuária em 5 milhões de cabeças, por outro lado contribuiu para intensificar tal exploração.

O melhoramento genético dos grãos coube ao Estado (através do Inta) e às empresas multinacionais, estas, em especial, produtoras de sementes híbridas de milho e girassol.

A figura do contratista ocupa lugar de destaque na organização da produção. O contratista é um empresário capitalista que concentra seu capital em maquinaria, alugando a terra para a exploração. A diferença entre este empresário e o da forma trinitária clássica é que, na Argentina, o pagamento da renda da terra tem um mecanismo de risco embutido, qual seja, o de remunerar o dono da terra com parte da própria produção. Assim, o risco fica dividido entre o proprietário da terra e o contratista.

Dois importantes vetores para a sustentação e prolongamento da "Revolução Pampiana" foram a queda dos direitos de exportação durante 1978 a 1981, e a demanda adicional representada pelas volumosas compras da Rússia, submetida ao embargo comercial pelos EUA a partir de 1979. A partir deste ano, o comprometimento das exportações argentinas com a Rússia chegou a $50 \%$ do total, situação que se prolongou até $1983 / 84$. Atualmente a participação caiu abaixo de $25 \%$.

O aprol undamento da "Revolução Pampiana" acabou sendo refreado pelos seguintes elementos:

- deterioração dos preços internacionais de commodities agrícolas;

- queda da fertilidade natural e da fertilidade residual proporcionada pela pecuária;

- alto custo financeiro;

- uso dos direitos de exportação como política fiscalista

do Governo;

- esgotamento das inovações tecnológicas;

- problemas estruturais para exportação de produtos argentinos.
A queda dos preços internacionais das commodities agrícolas, por conta da deterioração do poder de compra em escala mundial e, mais recentemente (no atual ano comercial), a guerra de subsídios entre a CEE e os EUA afetam negativamente a rentabilidade das explorações argentinas, com o que o estímulo de mercado se esvai.

O esgotamento da fertilidade natural e residual dos solos, provocado por explorações sucessivas de lavouras em terras ocupadas por pastagens, acentuou-se com a generalização do contratista na medida em que os contratos são de curto prazo, suficientes para cobrir uma safra, quando muito duas. Nestas condições, o contratista não tem compromissos, seja com práticas de manejo para conservação do solo, seja para recuperar-lhe a fertilidade.

$O$ alto custo financeiro para obtenção de empréstimos bancários tem freado o ímpeto da modernização, uma vez que a agricultura argentina de grãos é integrada ao mercado e literalmente monetarizada. Juros altos impõem barreiras muitas vezes intransponíveis, o que acaba acarretando sucateamento de máquinas e equipamentos agrícolas, redução na compra de sementes selecionadas e compressão das despesas com combustíveis (o item do custeio mais expressivo), defensivos e herbicidas.

O fato de a agricultura argentina apresentar-se secularmente como exportadora líquida de alimentos cristalizou uma postura fiscalista do governo federal, através da cobrança dos direitos de exportação. Na prática, o Governo estabelece câmbios diferenciados sobre

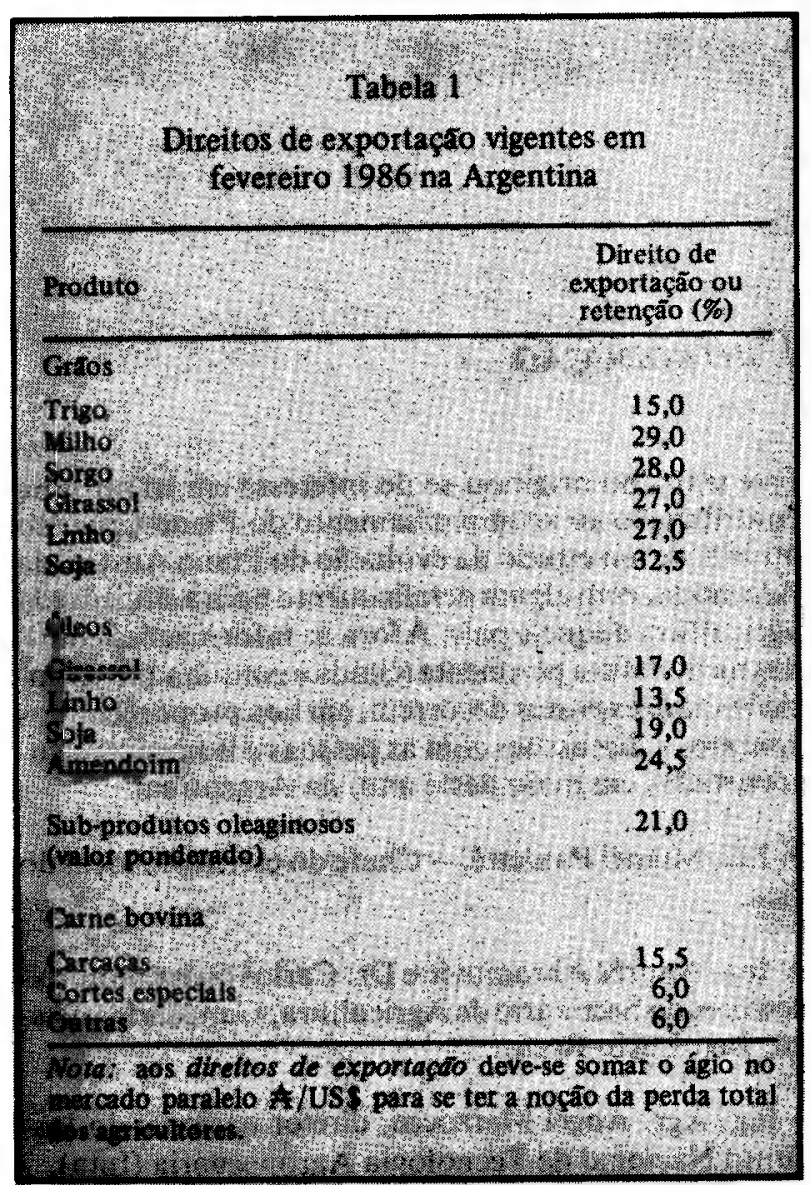


uma determinada pauta de produtos como forma de arrecadação fiscal.

No auge da "Revolução Pampiana" (entre 1978 e 1981) eles representavam $1 \%$ ou menos da massa de recursos tributários federais. No triênio $83 / 85$, esta participação variou de 9,5 a 16,5\%. Dados dos três primeiros trimestres de 1985 informam que tais direitos de exportação constituem a terceira fonte mais importante de tributos federais para o país.

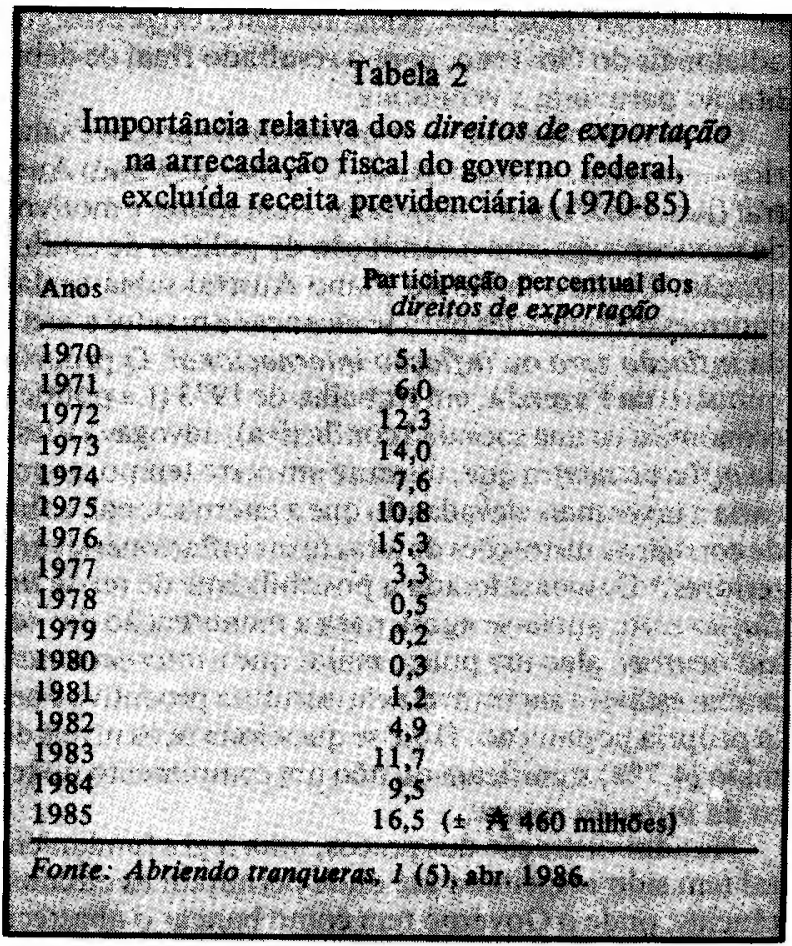

Do ponto de vista da exportação de grãos, a Argentina tem problemas estruturais sérios na infra-estrutura portuária e de navegação, pois seus portos têm limitação para receber embarcações de grande calado. As perdas relativas em que incorre a Argentina referem-se a custos unitários mais altos.

\section{O PLANO AUSTRAL}

\subsection{Concepção de heterodoxia}

As diversas tentativas de reordenar a economia argentina, antes do Plano Austral, foram do tipo ortodoxo, ou seja, desvalorização cambial acompanhada de políticas monetária e fiscal para possibilitar a absorção interna dos impactos, o que redunda em contração da economia.

A desesperança com o uso dos instrumentos disponiveis para, simultaneamente, debelar o processo inflacionário e possibilitar a consolidação das precondições de crescimento econômico levou à visão do que Rozenwurcel (D.1) chama de neo-estruturalismo, e daí ao heterodoxismo como forma alternativa de tratar o problema. Entre outras coisas se reconhece que nem todos os preços na economia são simplesmente produto da inte- ração das forças de oferta e procura (preços exógenos, flexprice, etc.) tal como preconizam os neoclássicos. Com isso quer-se destacar preços que são fixados pelos empresários (preços endógenos, fixprice, etc.). Além disso, entende-se que os processos inflacionários das economias latino-americanas apresentam um caráter fortemente inercial. Estas são duas posições que irão influenciar a montagem dos programas heterodoxos de estabilização: a) controle dos preços dos produtos de setores oligopolizados por um período longo, quando não de forma definitiva e permanente; b) eliminação da indexação como mecanismo generalizado na economia.

Dada a base de compreensão sobre a estrutura econômica e sobre o processo específico da inflação nos países latino-americanos, a preocupação inicial para implantar o Plano Austral - e que deve ser comum a qualquer medida semelhante - foi a de investigar os preços relativos. Os preços relativos, num determinado momento, mostram como os diversos agentes, setores, empresas, se situam uns frente aos outros em termos de poder de compra, ganhos e perspectivas de acumulação. Quanto maior a simultaneidade dos reajustes nos preços nominais, menos problemas de preços relativos. ${ }^{1}$ Embora o governo argentino não tenha expendido declaração oficial nenhuma sobre o assunto, é possível observar-se um senso comum em termos de que a desvalorização cambial, $o$ ajuste de tarifas de serviços públicos e alta do preço da carre promovidos antes da implantação do Plano Austral visaram ajustar preços relativos de setores importantes da economia. A correção deste último deve levar em conta um "atraso" de quase $50 \%$ dos produtos agropecuários em relação aos não-agropecuários, em junho/85.2 Some-se a isso o reajuste salarial de $22,6 \%$ e de $25,1 \%$ para aposentados, ainda em junho.

As linhas básicas do Plano Austral são as seguintes:

a) congelamento generalizado de preços, salários, rendimentos e tarifas, inclusive taxas de câmbio, por tempo indeterminado;

b) reforma monetária, com nova moeda de curso legal, o Austral (A);

c) mecanismo de conversão entre a nova e velha moeda para arbitrar as relações entre credores e devedores locais;

d) promessa de não-emissão para financiar o déficit fiscal; opção de utilização de empréstimos externos para este fim. Foi fixada a meta de reduzir o déficit fiscal, em um ano (nov. 1984 - fins de 1985 ), de 11,4 para $2,5 \%$ do PIB;

e) embora não faça parte propriamente dita de um plano heterodoxo, a manutenção da taxa de juros em patamares próximos a 70\% a.a. pode ser considerada um ponto importante do Plano Austral, dada a conveniência de repatriar capitais argentinos desviados para o exterior e evitar-se a formação de estoques especulativos.

\subsection{Desempenho da economia sob o Austral}

O desempenho da economia argentina, após a implantação do Plano Austral, pode ser visto através do comportamento de quatro indicadores básicos: taxa de câm- 
bio, déficit fiscal, movimento de preços e salários, e monetarização da economia.

A taxa de câmbio é considerada pelo próprio Governo como um indicador com êxito do Austral, seja pela estabilidade da nova moeda frente ao dólar, seja pelo baixo diferencial entre os mercados oficial e paralelo para compra e venda de dólares. Assim é que, desde junho de 1985, o ágio uma só vez atingiu $18 \%$, mantendo-se em um valor médio de $12 \%$. A taxa de juros de US $\$ 1.00 / 0,80$ pôde ser mantida fixa até início de abril de 1986 (portanto, durante quase dez meses), quando sofreu a primeira desvalorização. De 7 de abril até 6 de junho, o Austral foi desvalorizado cinco vezes num total de $8,04 \%,{ }^{3}$ e 0 ágio caiu para a metade daquela ordem de grandeza. 4

A manutenção da taxa de câmbio fixa por um bom períndo e a estreiteza da brecha cambial se devem, em grande medida, à política de administração da taxa de juros internos em patamares muito elevados. Estima-se que a venda de dólares para investimento em Austrais tenha proporcionado, de jun. 1985 a maio/1986, ganhos da ordem de $80 \%$. Dessa maneira, a conduta especulativa permanece, com a inversão dos termos: agora, a "bicicleta financeira" - como os argentinos a chamam - consiste em vender dólares e comprar austrais para aproveitar as taxas de juros de aplicações de curto prazo e não mais a troca de pesos por dólares como no período inflacionário anterior. Como neste contexto não se materializam as oportunidades de investimento, uma considerável massa de recursos permanece em estado potencial, servindo apenas para a rolagem diária da dívida do Governo. 5

O déficit fiscal teve uma evolução favorável mesmo não tendo atingido a meta fixada. Por efeito direto do choque tarifário que antecedeu o Plano Austral, da manutenção dos direitos de exportação e de importação, e da poupança forçada, a receita fiscal passou de 21,4 para $27,8 \%$ do PIB do primeiro para o segundo semestre de 1985. Esta arrecadação adicional, somada aos empréstimos externos para combater o déficit, concorreram para reduzi-lo de 12,75 para $4,5 \%$ do PIB neste mesmo período. 6

Este fato que, em si mesmo, é positivo, deixa algumas dúvidas quanto à sua sustentação a médio e longo prazos, não só porque o aumento da arrecadação fiscal encontra cada vez mais um número crescente de opositores que $o$ transformam em objeto político de questionamento da ação governamental, mas também porque a receita não vem sendo utilizada de forma significativa para alavancar o desenvolvimento, mas sim para proporcionar liquidez ao caixa do Governo. Um instrumento de política econômica de caráter produtivo, que poderia servir para dinamizar a produção, está representado por um sistema de incentivos fiscais que movimentará, em 1986, montante de recursos correspondente a $15 \%$ da receita tributária, ou da ordem de $2,6 \%$ do PIB, fundamentalmente para promoção industrial $(81 \%)$. Entretanto, um relatório do PMI sobre este sistema mostrou que o mesmo, por estar controlado em sua maioria pelos governos provinciais (estaduais), deixa de seguir orientação no sentido de criação de oportunidades industriais multiplicadoras de emprego, como deveria ser o caso. ${ }^{7}$
Afora esses aspectos, o caso mais grave do déficit público está no seu componente formado pelo pagamento da divida externa. Já em 1984, o Governo havia assumido boa parte da dívida externa (em 7.9.84, o setor público devia US $\$ 31,6$ milhões contra US $\$ 12,8$ bilhões do setor privado - BCRA, Comunicado n: 645), o que é um complicador não só para administrar o déficit, mas também para o índice de preços e para a retomada do crescimento. A situação se complica na medida em que os saldos comerciais não são suficientes para o pagamento dos serviços. Isto, evidentemente, exige esforços adicionais do Governo, com o resultado final de debilitação para toda a economia.

O terceiro indicador - movimento de preços e salários - mostra, no decorrer de 11 meses de Plano Austral (jun.1985/maio 1986), fatos alentadores e motivos de preocupação com a condução da política de estabilização. Desde o início do Plano Austral sabia-se das enormes dificuldades para se alcançar e manter a meta da inflação zero ou inflação internacional. O próprio ministro da Fazenda, em trabalho de 1973 (La política económica en una sociedad conflictiva), advogava a tese da inflação neutra que, durante um certo tempo, avançaria a taxas mais elevadas do que a internacional, a fim de corrigir as distorções de altas taxas inflacionárias anteriores. ${ }^{8}$ Desconsiderada a possibilidade de ter-se inflação zero, apela-se agora para a manutenção das $t a-$ xas neutras, algo um pouco maior que a internacional, porém estável e suportável pela estrutura produtiva e pela própria população. Hoje se questiona se os níveis de maio $(4,7 \%$ ) significam ou não um rompimento do teto da inflação neutra.

$\mathrm{Na}$ administração dos preços, uma regra fundamental tem sido respeitada até onde permitam as circunstâncias: onde o Governo tem como bancar o abastecimento, o controle sobre os preços pode ser bastante rígido; onde, porém, não há como prover o adequado abastecimento, os graus de controle são mais flexíveis. A importância relativa do setor (formador de preços, oligopolizado, papel influente na composição do índice de preços, etc.) também foi levada em conta para a política de congelamento. Em função deste controle, os resultados obtidos até maio vinham sendo considerados satisfatórios, quando comparados com as taxas inflacionárias anteriores ao Plano Austral. Assim é que, de jan. a jul.1985, a taxa inflacionária mensal andou ao redor de $20-30 \%$; em jul.1985, caiu para $6 \%$; já entre ago. 1985 e fev. 1986 , entre 2 e $3 \%$, e de mar. a maio 1986, entre 5 e $6 \% .{ }^{9}$ Excluído o resultado de jul. 1985 , influenciado pela metodologia de medição do índice, que mede a variação de preços entre os dias 15 de dois meses subseqüentes, há uma preocupação de que o sentido crescente dos valores assuma um perfil exponencial e, por isso mesmo, venha a eliminar os ganhos até então verifícados. $\mathrm{Na}$ época em que o Executivo definiu a taxa de $28 \%$ a.a. na proposta orçamentária para 1986, os empresários avaliavam-na como inatingível, acreditando em algo entre $40-50 \%$ anuais. Se se anualizar a taxa inflacionária verificada até abril, o valor alcança 57\%.10 Detalhe metodológico a ser registrado: estes valores representam ponderação entre as taxas ao nível do atacado e do consumidor. Para perceber a diferença pronunciada entre estas, resume-se o quadro geral de evolução dos diferentes índices de preços. 


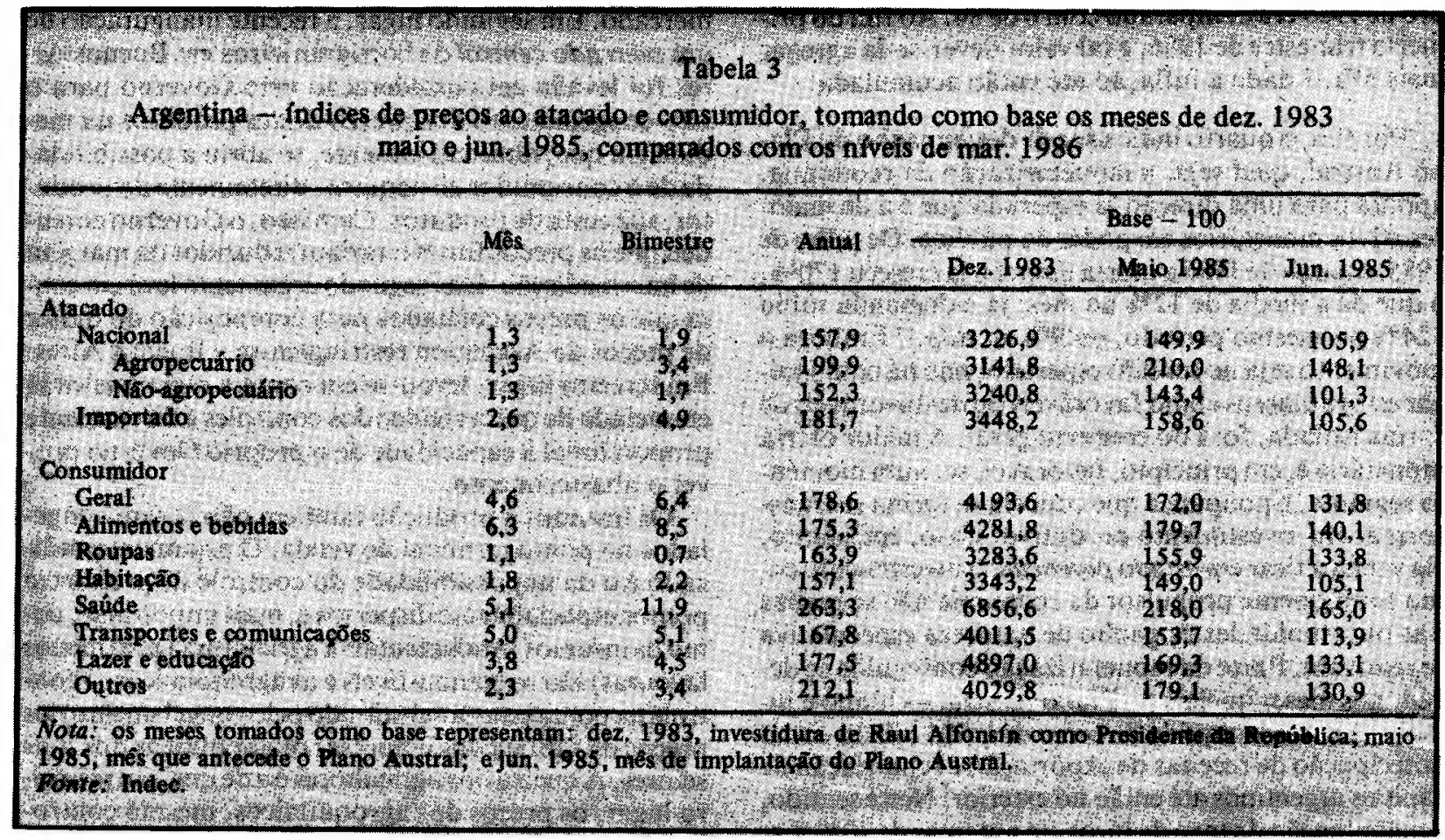

a tabela permite algumas constatações:

a) os preços no atacado, para qualquer base, evoluíram menos do que os preços ao consumidor. A diferença entre ambos, que girava ao redor de $30 \%$ por época da investidura de Alfonsín na Presidência, caiu para $15 \%$ no mês que antecedeu o Plano Austral, tendo voltado ao patamar de $25 \%$ após sua implantação. Parte da explicação do "atraso" dos preços ao nível do atacado reside na maior eficiência do controle que é possível ter-se aí em relação à prática de preços do varejo, cuja estrutura é extremamente pulverizada;

b) internamente aos preços ao atacado, os da agropecuária destacam-se dos demais, de forma flagrante, quando a referência é maio ou jun.1985, exatamente o contrário quando a comparação toma como marco a posse de Alfonsín. Isso mostra que os preços da agropecuária, no atacado, estavam relativamente desfavoráveis entre a posse de Alfonsín e a decretação do $\mathrm{Pla}$ no Austral, mas que, após esta data, houve um movimento de recuperação bastante claro no que concerne à sua relatividade com preços de outros setores;

c) na estrutura interna dos preços ao consumidor os destaques são, por um lado, para alimentos e bebidas e despesas com saúde, que sobem mais do que a média, e por outro, para habitação e transportes e comunicação, que sobem menos do que a média. No corte temporal, verifica-se que o item alimentos e bebidas já era e continuou sendo maior do que a média, o mesmo ocorrendo com despesas de saúde;

d) tanto no caso dos preços ao atacado quanto no caso dos preços ao consumidor, o setor agropecuário pressiona os índices respectivos. No período que se inicia com a implantação do Plano Austral, a explicação está claramente na decisão do governo de: 1 . não contro- lar preços de frutas, hortaliças e legumes; 2. reajustar preços de alguns produtos como carne e leite; 3. congelar preços de apenas alguns derivados em setores como o da suinocultura, deixando os preços dos demais flutuar livremente. 1

Dentre todos os preços, os salários constituem caso a parte para registro. De início, assim como os preços, os salários também foram congelados. A política de estabilização contida no Plano Austral foi vaga quanto aos reajustes salariais. Acredita-se que a definição preliminar e de surpresa - como foi a implantação do Austral - de uma política de reajustes salariais poderia deixar o Governo sem flexibilidade para negociar este aspecto específico com as classes trabalhadoras, representadas pela CGT. Sabendo que a CGT é dominada pelo peronismo - oposição ao Governo - o Executivo tratou de constituir uma Conferencia Económica y Social para tratar das grandes questões nacionais que afetam trabalhadores e empresários, das quais o salário é a mais importante delas. Os pontos de acordo neste Conselho tornaram-se raros, e ainda no início deste ano, a CGT convocou greve geral dos trabalhadores para dernonstrar a insatisfação da classe diante da queda do poder aquisitivo. Diante da falta de acordo das partes, o Governo estabeleceu, para o trimestre abr./jun. 1986, reajustes de $5 \%$ para o setor público e $8,5 \%$ para trabalhadores do setor privado, e elevou o "salário de garantia". Com isso, a insatisfação não foi resolvida, sendo apenas adiada, de tal forma que novos movimentos grevistas poderão ser verificados. Ademais, ainda em maio de 1986, a CGT resolveu abandonar a referida conferência diante da negativa de se negociar um reajuste para os aposentados, uma vez que a única alternativa técnica para concedê-lo, segundo o próprio Governo, seria através do aumento de $100 \%$ da cota de previdência patronal (de 7,5\% para $15 \%$ ). A deterioração dos salários no setor público era de $33 \%$, quando o mês de dezem- 
bro de 1985 era comparado com o de 84. Ao fim do primeiro trimestre de 1986, a tal valor dever-se-ia agregar mais $5 \%, 12$ dada a inflação até então acumulada.

Por fim, o quarto indicador de desempenho do Plano Austral, qual seja, a monetarização da economia, aponta para uma direção já esperada que é a de maiores ativos monetários em poder do público. De julho de 1985 a março de 1986 a oferta monetária cresceu $170 \%$, o que dá a média de $12 \%$ ao mês; já a demanda subiu $124 \%$ no mesmo período, ou $9 \%$ ao mês. ${ }^{13}$ Embora o movimento seja no sentido esperado, não há como julgar estes números como favoráveis ou desfavoráveis de forma isolada, fora do contexto geral. A maior of erta monetária é, em princípio, favorável, se, num momento seguinte, a poupança que com ela se forma se transformar em investimento produtivo. Caso, entretanto, ela venha a ficar em estado potencial, o investimento como componente propulsor da economia não se realiza e as oportunidades de ganho de natureza especulativa se reativam. Parte da monetarização conseguida se deveu, nos meses iniciais do Plano Austral - junho e julho - à entrada líquida de cerca de US\$1 bilhão como antecipação de receitas de exportação e repatriação de capitais argentinos até então no exterior. Neste sentido, a manutenção da taxa de juros em patamar de $70 \%$ a.a. contribuiu decisivamente. Entretanto, o que num primeiro momento é favorável, acaba por se transformar em transtorno se as forças produtivas não encontram um caminho alternativo de expansão.

\subsection{Fases do Austral}

Qualquer plano de estabilização que adote o corte heterodoxo presumivelmente apresentará uma primeira fase de preços e salários congelados, quando não em queda, e logo após uma fase de transição de volta à normalidade de mercado.

A primeira fase do Plano Austral - a do congelamento - vai de jun. $/ 85$ a fev. $/ 86$, quando predomina a idéia da rigidez dos controles. A segunda fase, mais curta - a da flexibilidade - se traduz por ajustes seletivos em combustíveis, alguns alimentos e salários, indo de fevereiro a abr./maio 1986. Por fim, a terceira fase - a de administração de preços - teve início com a edição da Resolução n: 50, de 14.5.86, adiante comentada.

\subsection{O caso particular da agricultura}

Os comentários sobre o impacto do Plano Austral na agricultura argentina serão feitos, sempre que possível, obedecendo ao esquema das três fases já mostrado. $\mathrm{Na}$ fase do congelamento, em nenhum momento o Governo enquadrou os preços das frutas, hortaliças elegumes. Explicitamente, o Governo os deixou de fora do congelamento. Algumas razões foram invocadas para este procedimento: em primeiro lugar, a estacionalidade de produção destes produtos é muito marcada. Ou seja, sob condições climáticas mais severas, há épocas em que a oferta se anula e, portanto, deixa de haver cotações de mercado. Assim, o congelamento de preços em junho de 1985 , por definição, não afetou produtos destes grupos que, naquela época, não eram cotados no mercado. Em segundo lugar, a recente inauguração de um mercado central de hortigranjeiros em Buenos Aires foi levada em consideração pelo Governo para o não-congelamento dos preços destes produtos na medida em que, alternativamente, se abriu a possibilidade de o consumidor ali adquirir, diretamente do produtor, sua cesta de produtos. Com isso, o Governo entendeu que os preços finais estariam reduzidos da margem de intermediação. Este segundo argumento leva em conta que os preços coletados para composição do índice de preços da Argentina restringem-se a Buenos Aires. Em terceiro lugar, levou-se em conta a regra básica já enunciada de que a rigidez dos controles é diretamente proporcional à capacidade de o próprio Governo prover 0 abastecimento.

Os insumos à produção também não foram congelados no ponto terminal de venda. $\mathrm{O}$ argumento utilizado é o da impossibilidade do controle de preços em pontos espacialmente dispersos e, mais importante, como os insumos fundamentais à agricultura (pelo menos lavouras) são os combustíveis e os agroquímicos, o controle na ponta estaria substituído pelo congelamento dos preços de fábrica das empresas oligopolíticas dos dois setores. A queixa dos agricultores é a de que, em primeiro lugar, os preços dos agroquímicos, mesmo controlados na produção, foram alterados; em segundo, que preços de sementes não foram congelados e, terceiro, que os preços dos serviços em geral desconheceram o Plano Austral. A situação não se agravou porque a baixa rentabilidade dos produtos exportáveis determinou um arrefecimento pela demanda de insumos.

Durante toda a fase do congelamento, o país conviveu com distorções nos mercados de carnes (bovina e suína) tais como mercado negro, sobrepreço, falta de produtos etc. $\mathrm{O}$ agravamento destes problemas levou o Governo a rever o congelamento para os casos mais graves, tendo liberado o preço do gado em pé - no que apenas convalidou o mercado - e aplicado $15 \%$ de reajuste, ao nível de consumidor, para os cortes de primeira e manutenção do congelamento dos preços para os cortes populares. No caso do leite, o reajuste ao produtor foi concedido em duas etapas, sendo de $15 \%$ a partir de 20.2.86 e de $9 \%$, a partir de 20.3.86. Para o consumidor, o reajuste foi de $9 \%$.

No caso das carnes de suínos, a solução encontrada foi o congelamento seletivo de alguns derivados, deixando outros livres para permitir rentabilidade sustentável ao nível da produção. Já a produção de aves foi literalmente inviabilizada com o não-controle dos preços de seu principal insumo, as rações. Por conta disso, a oferta foi interrompida, o setor entrou em crise e o país passou a importar frangos abatidos.

Caso particular de interesse da agricultura reside nos direitos de exportação. Como medida fiscalista imposta a mais de uma geração ao setor, ela não se enquadra como instrumento de estabilização da economia. Mas nessa ocasião, como forma de ceder às pressões - radicalizadas por conta da depressão de preços internacionais das commodities agrícolas exportadas pela Argentina - o Governo fez algumas concessões, reduzindo alíquotas de direitos de exportação sobre alguns produtos, prometendo a unificação das mesmas para a safra $1986 / 87$, na marca de $15 \%$, para os principais. 


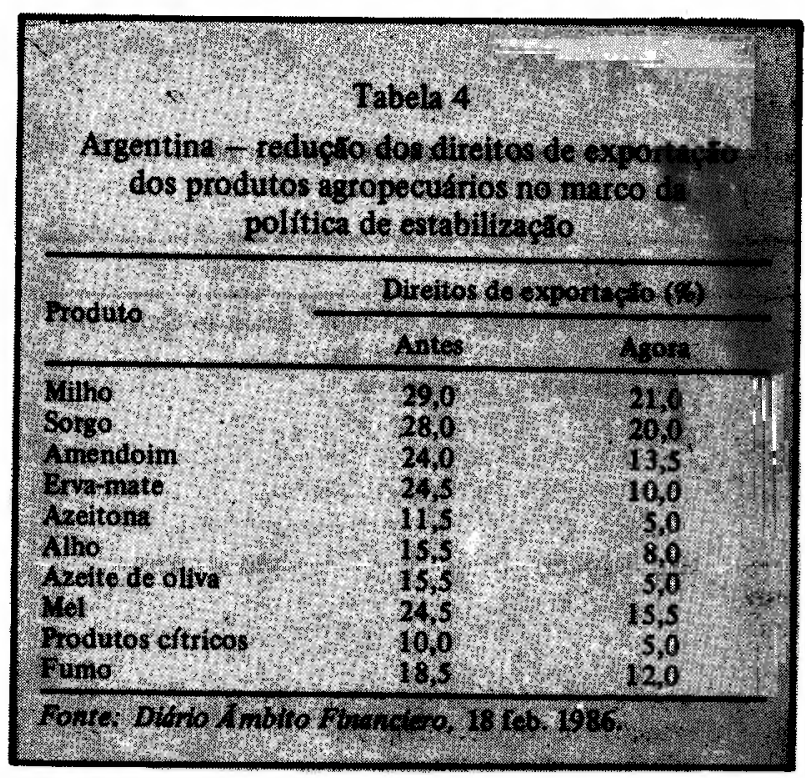

A estrutura produtiva na Argentina fornece indicadores importantes para se perceber o real impacto do Austral sobre o setor. Do ponto de vista de preços ao produtor, o funcionamento do mercado internacional e a administração dos direitos de exportação são muito mais importantes do que o próprio Plano Austral, já que a Argentina é um país essencialmente exportador de grãos e derivados. O inverso ocorre nos casos da carne e nos produtos regionais, voltados na sua maioria para o mercado interno.

Como medidas compensatórias à perda de renda, $o$ Governo acenou para os agricultores com a promessa de implementar créditos de investimentos a partir de empréstimos do Bird; com a revisão do modelo institucional do Inta (Instituto Nacional de Tecnologia Agropecuária), buscando maior eficiência técnico-administrativa e participação do público destinatário; com a política de minidesvalorizações cambiais, o que aumenta a receita final dos agricultores de grãos em austrais e, finalmente, com a perspectiva de substituir os direitos de exportação por impostos sobre a terra, de forma a incentivar a produtividade e a eficiência.

\subsection{Estratégia de descongelamento (política de administração de preços)}

Se Abraham Lincoln fosse economista ele certamente teria dito: "Pode-se controlar todos os preços por algum tempo, pode-se controlar alguns preços durante todo o tempo, mas não se pode controlar todos os preços durante todo o tempo."

O descongelamento na Argentina, caracterizado como uma política de preços administrados, foi implantado oficialmente através da Resolução no 50 , da Secretaria de Comércio Interior (SCI), em 14 de maio de 1986, a partir de quando se inicia a terceira fase do Plano Austral.

Trata-se de um conjunto de regras para regulamentar o repasse de custos aos preços dos produtos. Para tanto, divide o período que vai desde a implantação do Plano Austral até a data de promulgação da Resolução $\mathrm{n}$. $50 \mathrm{em}$ dois subperíodos, para os quais define procedimentos básicos de encaminhamento de solicitações.
I. Para o primeiro subperíodo (12.6.85 a 31.3 .86$)$ estabelece:

1. reajustes aceitáveis:

a) de matérias-primas nacionais, para as quais a SCI tenha oficialmente aprovado o reajuste. Preços de insumos e matérias-primas não-sujeitos ao controle não podem ser levados em conta na solicitação de reajuste de preços dos produtos finais e, portanto, eventuais atrasos dai decorrentes não podem ser minorados ou eliminados;

b) de matérias-primas importadas, seja por conta de alteração da paridade cambial, seja por alteração nos direitos de importação.

\section{2. forma de repasse:}

os custos acrescidos deverão ser repassados aos preços segundo sua exata incidência no custo total, definida por uma planilha-padrão de custos que regulamentará os cálculos, na data-base de 31.7.85. Uma vez apurado o percentual de aumento dos preços, o mesmo deverá ser distribuído nos meses de maio e junho de $1986 \mathrm{em}$ alíquotas mensais iguais.

II. Para o segundo subperíodo (1.4 a 14.5.86) estabelece:

1. reajustes aceitáveis:

a) de matérias-primas nacionais e importadas, tal como definidos anteriormente;

b) de serviços públicos e de combustíveis, para os quais a SCI tenha emitido autorização expressa para algum reajuste anterior;

c) de salários, encargos sociais, comissões de venda e trabalho de terceiros:

d) de fretes.

2. forma de repasse:

a) os custos acrescidos deverão ser repassados aos preços segundo sua exata incidência no custo total, definida por uma planilha-padrão de custos que deverá regular os cálculos na data-base de 31.3.86;

b) os custos acrescidos referentes a 1.a, 1.b e 1.d poderão ser repassados de uma só vez;

c) os custos acrescidos referentes a 1 .c serão reduzidos de $0,4 \%$ e repassados, no mês de junho de 1986 , aos preços finais; no caso de futuros aumentos deste item, os repasses aos preços finais poderão ser feitos em um só mês, aplicando-se, neste caso, o redutor de $0,2 \%$;

d) no caso dos custos referentes ao item 1.d, o percentual não pode ultrapassar o apurado pelo Índice de Preços ao Consumidor, em seu subitem Transportes e comunicação, conforme definição do Indec.

Independente do caso, a estrutura de custos apresentada pela Resolução n: 50 penaliza o endividamento excessivo das empresas ao não assumir custos financeiros superiores ao de uma proporção de 1:1 entre capital de trabalho próprio e dívida.

Uma vez definidos os itens cujos reajustes serão aceitáveis e as regras de repasse dos mesmos, a Resolução n. 50 tipifica as empresas para enquadramento das solicitações. Basicamente, os grupos estão assim constituídos: 


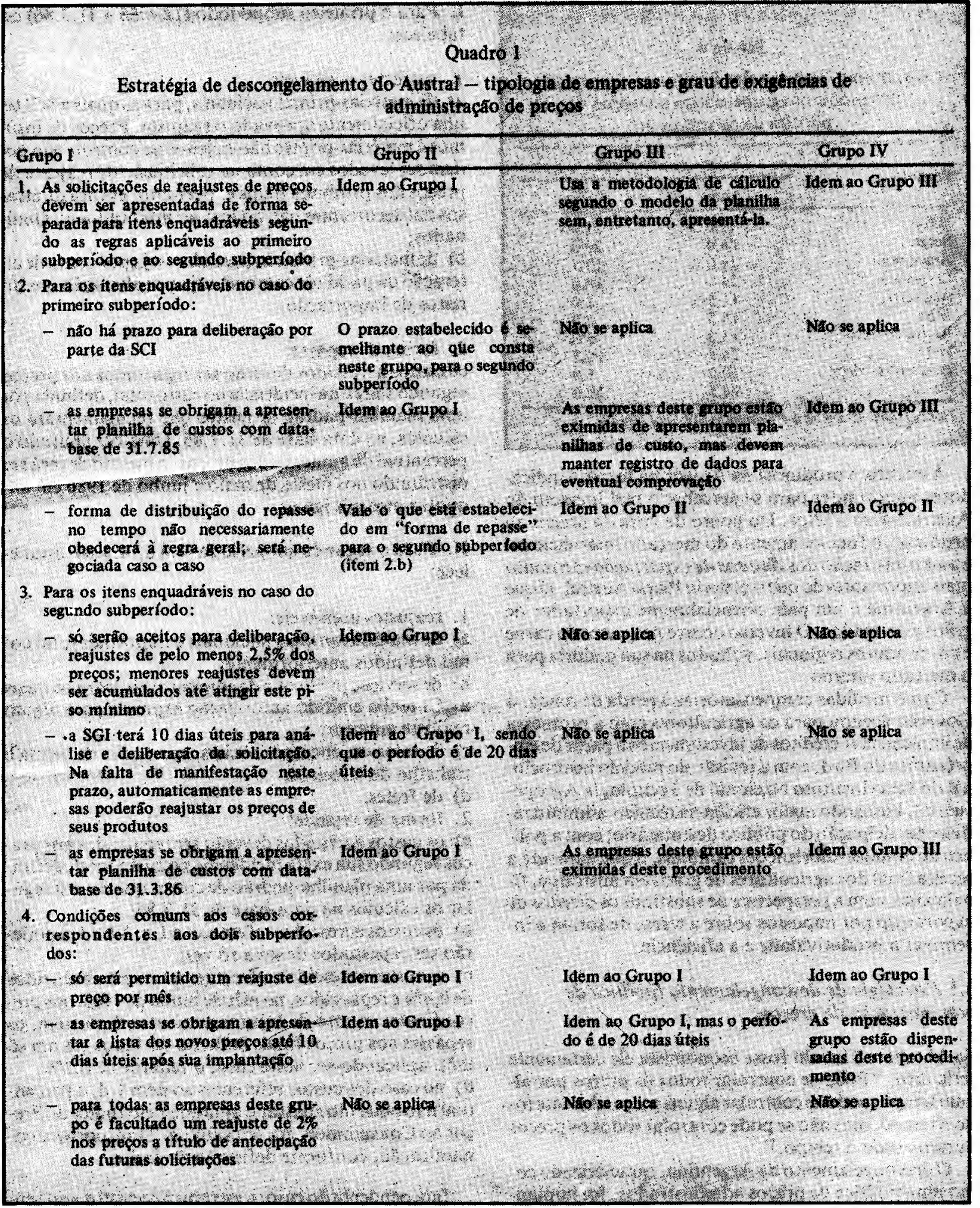

1. empresas líderes -500 empresas nominalmente citadas pela resolução, enquadráveis como oligopólios/monopólios, produtoras de insumos básicos e empresas formadoras de preços.

2. as não-enquadráveis no primeiro grupo estão agrupadas em três outras categorias, por faturamento bruto anual no mercado interno:

2.1 superior a 12 milhões (ou US\$ 10 milhões);

2.2 entre 6 e 12 milhões (ou de US\$ 5 a 10 milhões):
2.3 inferior a 6 milhões (ou menos de US\$ 5 milhões).

Para cada uma delas, o quadro a seguir resume as disposições legais da política de preços administrados.

Afora estas definições específicas, a Resolução n: 50 estabelece alguns princípios e mecanismos, seja para evitar transgressão às regras criadas, seja para evitar manipulação das informações, seja para enfrentar situações como a colocada por produtos novos, sem simila- 
res anteriores com os quais se possa comparar preços para definir reajustes.

Como definição final ficam impedidos de alterar seus preços sem prévia autorização da SCI as escolas particulares, os bares, restaurantes, confeitarias, as casas de comidas prontas, os estabelecimentos de produção e comercialização de produtos medicinais de uso humano e os prestadores de serviços de medicina em associações (ou pagos em forma de mensalidade).

Embora não-regulados pela referida resolução, continua em vigor o regime de preços máximos para meia centena de produtos da cesta básica com promessa de liberação gradativa ao longo deste ano, de forma que em 31.12.86 nenhum deles mais esteja sob este tipo de controle. Para este conjunto de produtos foi concedido um reajuste geral entre 4,2 e 4,3\%, em 19.5.86. 14

Os comentários sobre o descongelamento são em geral restritivos, pois se entende que a rigidez acabou sendo maior que a esperada, além do que tamanho grau de complexidade na operação deste instrumento acabará por tornar as decisões mais complicadas, o que será prejudicial às empresas ali enquadradas. Outro aspecto a lembrar é o sentimento de que, de uma forma ou de outra, as empresas lideres (Grupo I) nunca mais deixarão de ser controladas, dada sua importância no contexto da economia argentina. Não se justifica que estatais do porte de Aerolineas Argentinas, Obras Sanitárias, Gás del Estado e Entel não estejam no Grupo I, se bem que ali esteja a YPF. Por fim, são setores claramente prejudicados os das empresas que trabalham com insumos cujos preços não foram congelados, pois não terão seus acréscimos em custos reconhecidos (é o caso de têxteis, papel, celulose, legumes e frutas industrializados) $\mathrm{e}$ as endividadas, seja para prover capital de giro, seja para investir na melhoria e/ou ampliação de produção. $\mathrm{O}$ fato positivo é o fim do congelamento e, com isso, a crença de que outras formas de negociação à margem da Resolução n. 50 terão lugar.

\section{COMENTÁRIOS CONCLUSIVOS}

Decorrido um ano, a experiência da Argentina com o Plano Austral não é exatamente o que os seus simpatizantes gostariam que fosse. Há problemas; alguns simples, outros extremamente complexos para serem solucionados.

De antemão, cumpre registrar que nenhum plano de estabilização opera milagres na economia. A Argentina partiu de uma situação crítica, na qual os principais ingredientes eram a recessão e a inflação. $O$ comportamento da economia sob o Austral revelou que as medidas de um plano de estabilização de corte heterodoxo não têm vida longa e, mais ainda, em si não trazem nenhuma proposta renovada de desenvolvimento. Ou seja, por trás de um plano de estabilização não há nenhum novo modelo econômico, mas muito mais uma vontade política de enfrentar um quadro econômico crítico. Os desdobramentos colocados pela economia é que irão dizer se há como redirecionar o esforço nacional para o crescimento, através da poupança e do investimento sincronizados.

A fuga a uma solução ortodoxa evitando, com isso, o caminho direto à recessão, é correta. Entretanto, nu- ma situação de preços congelados, a condução da política monetária revelada, entre outras coisas, pelo comportamento da taxa de juros, também pode levar, por vias tortuosas, à situação recessiva, na medida em que o seu elevado nível se presta não mais do que à manutenção do dinheiro em estado potencial, sem sua necessária transformação em investimento.

A agricultura argentina que, por sua natureza secularmente excedentária, sempre se prestou à extração de riqueza para montar e diversificar o quadro econômico nacional, diante da queda do poder de compra da população e da depressão dos preços no mercado internacional - comandada pela guerra de subsídios entre os EUA e a CEE - não suporta mais a postura fiscalista governamental. Há sinais de desencanto e de sérias preocupações com a sustentação do processo produtivo nos padrões argentinos habituais. Em especial, parece ter chegado ao fim a vantagem relativa de terras naturalmente férteis, hoje dando sinais de esgotamento e de erosão, para os quais a saída natural é o investimento, o que, nas circunstâncias atuais de mercado, conspira contra a competitividade dos produtos argentinos no mercado internacional.

Mas que lições a Argentina oferece ao Brasil? Sem desconhecer os inúmeros pontos que diferenciam as economias dos dois países, entende-se que poderiam ser objeto de estudo para o nosso caso:

- a meta de conviver com um nível inflacionárío que não inviabilize o crescimento da economia diferente da inflação zero. Há que se definir, em função da história econômica de nosso país, umainflação de crescimento. Esta postura não significa, de maneira alguma, capitulação, mas sim maturidade e realismo;

- o nível da taxa de juros não deve ser tão alto quanto o da Argentina, mas também não tão baixo que dê a impressão de que, em determinado momento, o Governo resolva aplicar-lhe uma maxicorreção. Taxas muito baixas, ao contrário de estimular o investimento, podem afugentá-lo exatamente porque podem representar uma situação não-sustentável a médio e longo prazos. A experiência brasileira de mercados segmentados de crédito (rural, habitacional, da pequena e média empresas, de exportação) pode ser explorada ainda um pouco mais, através da diferenciação das taxas ali praticadas. Na medida em que a economia retome sua perspectiva de crescimento, seria de todo recomendável que a interligação destes mercados fosse sendo feita, preservando apenas aqueles julgados essenciais à correção de distorções inaceitáveis numa sociedade democrática;

- a garantia de que a dívida externa deixe de drenar recursos fundamentais ao nosso crescimento não pode ser colocada de lado. Na medida em que o próprio Governo assumiu boa parte da dívida privada, por aí potencializou os mecanismos inflacionários a um ponto além de suas próprias capacidades;

- a intervenção governamental nos mercados deve levar em conta a sua capacidade de prover o abastecimento que, por sua ação, se vê interrompido ou prejudicado. Aceita-se que no Brasil o grau de intervenção do Governo nos diversos mercados seja maior do que para a Argentina. O que não parece correto é estender tais mecanismos de intervenção além da própria capacidade de sustentar o funcionamento dos mercados em condições artificiais; 
- na medida em que amadureçam as condições para a discussão do congelamento, o modelo argentino - especialmente no que se refere aos setores oligopolizados (Resolução n: 50) - e o revigoramento do CIP serão duas peças básicas na montagem de nossa estratégia; - o descongelamento ainda é muito prematuro para ser discutido no Brasil de forma global, já que nossas principais safras já estão colhidas e/ou nossas importações já providenciadas. Assim, para os produtos de consumo massivo não há perspectivas de problemas insustentáveis. Entretanto, problemas particulares deveriam merecer tratamento específico na perspectiva de formar, pouco a pouco, uma situação compatível com taxas de inflação de crescimento. O leite, mesmo com subsídio, ainda é um problema. Os hortigranjeiros, ao fim da safra que estamos vivendo, se credenciam como outro problema para dentro em breve. Esta última é uma área na qual a excessiva interferência nos mercados parece ser danosa, pois não é possível ter-se controle sobre a oferta. Finalmente, o caso da safra 1986/87 deve merecer atenção especial porque, enquanto a decisão sobre o plantio (redução, mamutençțo, ampliação) se fará brevemente, sob os rigores do Plano Cruzado, a prática de comercialização ocorrerá após o primeiro aniversário do plano, entre março e junho de 1987. De forma simplificada talvez seja necessário simular o mercado mais liberado de 1987 agora em 1986, época das decisões fundamentais da safra vindoura;

- o momento presente é o de simultaneamente continuar administrando a política de estabilização - no sentido de consolidar um cenário favorável para o crescimento - e instrumentalizando o Estado brasileiro para apoiar, liderar e dar suporte ao desenvolvimento nacional, através de políticas de estímulo à produção e de incremento do emprego e renda nacionais, exatamente porque o plano de estabilização é apenas um passo inicial para a definição de uma nova opção de modelo econômico.

\section{REFERENNCIAS BIBLIOGRÁFICAS}

\section{Jornais}

Clarín, Buenos Aires, 20 ene., 15 mar., 11 abr., 11,13 a 15 y 17 mayo 1986 .

Clarin Arquitectura, 15 mayo 1986.

Clarín Económico, Buenos Aires, 11, 18 y 22 mayo 1986.

Clarín Rural, Buenos Aires, 15 y 22 feb, 8 mar. 24, 17 y 31 mayo 1986.
Diário Ámbito Financiero, Buenos Aires, 18 y 19 feb., 23 abr. 13, 14, 15, y 16 mayo 1986.

El Periodista de Buenos Aires, Buenos Aires, 11 y 17 abr., 16 y 22 mayo 1986.

Gazeta Mercantil, São Paulo, 14 e 20 maio e 9 jun. 1986.

La Capital, Mar del Plata, 15 mar. 1986.

La Nación, Buenos Aires, 22 feb. y 12 abr. 1986.

Los Andes, Mendoza, 4 y 12 mar. 1986.

Tiempo Argentino, Buenos Aires, 23 mar. 1986.

\section{Periódicos}

Abriendo Tranqueras, Buenos Aires, Crea - Zona Norte, $l$ (5), abr. 1986.

Boletín Informativo, Buenos Aires, Sociedad Rural Argentina, ene./feb. 1986.

Canedo, Daniel Fernández. Evaluación del Plan Austral. Realidad Económica, p. 13-26, s.n.t.

Conyuntura y Desarrollo, Buenos Aires, Fundación de Investigaciones para el Desarrollo, n. 84, ago.1985.

Giberti, Horário. El Programa Nacional Agropecuario (Pronagro). Realidad Económica, p. 36-44, s.n.t.

Informe Económico de Conyuntura, Buenos Aires, Consejo Profesional de Ciencias Económicas, jun./ago./set./oct./nov. 1985.

La Bolsa, Buenos Aires, Bolsa de Comercio de Buenos Aires, 8 (401/404), 3 ene. y 14 feb. 1986.

Modiano, Eduardo Marco. O choque argentino e o dilema brasileiro. Revista de Economia Política, São Paulo, Brasiliense, 6 (2): 77-90, abr./jun. 1986.

Precios Agropecuarios, Buenos Aires, Asociación Argentina de Consorcios Regionales de Experimentación Agrícola, n. 52 y 53, 11 mar. e 11 abr. 1986.

Revista de los Crea, Buenos Aires, Consorcio Regional de Experimentación Agrícola, abr. 1986.

Documentos sobre a reforma monetária argentina. $R e$ vista de Economia Política, São Paulo, Brasiliense, 6 (2): 137-146, abr./jun. 1986.

\section{Documentos}

Argentina. Dirección Nacional de Análisis de Precios. Metodología del Índice de precios al por Mayor. Análisis Global. s.n.t.

Ministerio de Economía. Programa Nacional Agropecuario. (Pronagro). 1984/87. Resumen. 
Buenos Aires, Secretaría de Agricultura y Ganadería, oct. 1984.71 p. (versión preliminar, mimeogr.)

Presidencia de la Nación. Lineamientos de una estrategia de crecimiento económico, 1985-1989. República Argentina, Secretaría de Planificación, 111 p.

Ministerio de Economía. Una proposta para la producción agricola nacional. Buenos Aires, Secretaría de Desarrollo Regional, s.d.

\section{Livros}

Arida, Pérsio, org. Inflação zero. Brasil, Argentina e Israel. Rio de Janeiro, Paz e Terra, 1986. 96 p.

Lopes, Francisco. O choque heterodoxo. Combate à inflação e reforma monetária. Rio de Janeiro, Campus, 1986. $185 \mathrm{p}$.

\section{Documentos já elaborados sobre a política de estabili- zação}

Embrater. Relações de troca da agricultura brasileira no periodo $75 / 84$, por Mauro Márcio Oliveira. Brasília, mar. $1986 a .10$ p. + anexos mimeogr.

. O programa de estabilização da economia brasileira e suas repercussões na agricultura, por Mauro Márcio Oliveira. Brasília, mar. 1986b. 18 p. mimeogr.

A agricultura e o cenário da estabilização econômica, por Mauro Márcio Oliveira. Brasilia, abr. 1986 e. 20 p. mimeogr.

1 Neste particular, a hiperinflação tende a tornar simultâneos todos os reajustes de preços nominais, reduzindo a quase zero o intervalo de tempo para a troca de preços.

2 Gómez, Evangelino. Mayores márgens de comercialización. Clarín Económico, Buenos Aires, 11 mayo 1986. p. 12.

3 Gazeta Mercantil, São Paulo, 9 jun. 1986.

4 Clarín, Buenos Aires, 14 mayo 1986.

${ }^{5}$ El Periodista de Buenos Aires, Buenos Aires, 2(88): 2-3, 16-22 mayo 1986.

${ }^{6}$ Diário Ámbito Financiero, Buenos Aires, 14 mayo 1986.

${ }^{7}$ Diário Ámbito Financiero, Buenos Aires, 14 mayo 1986.

8 Clarín Económico, Buenos Aires, 11 mayo 1986.

9 Ahusborde, Hugo. Complicaciones en el plan austral. Diário Ámbito Financiero, Buenos Aires, 14 mayo 1986. p.7.

10 Clarín, Buenos Aires, 11 mayo 1986.

11 Para maiores detalhes, ver Gómez, E. op. cit.

12 Clarín Económico, Buenos Aires, 11 mayo 1986.

13 Ahusborde, Hugo. op. cit.

14 Gazeta Mercantil, São Paulo, 20 maio 1986.

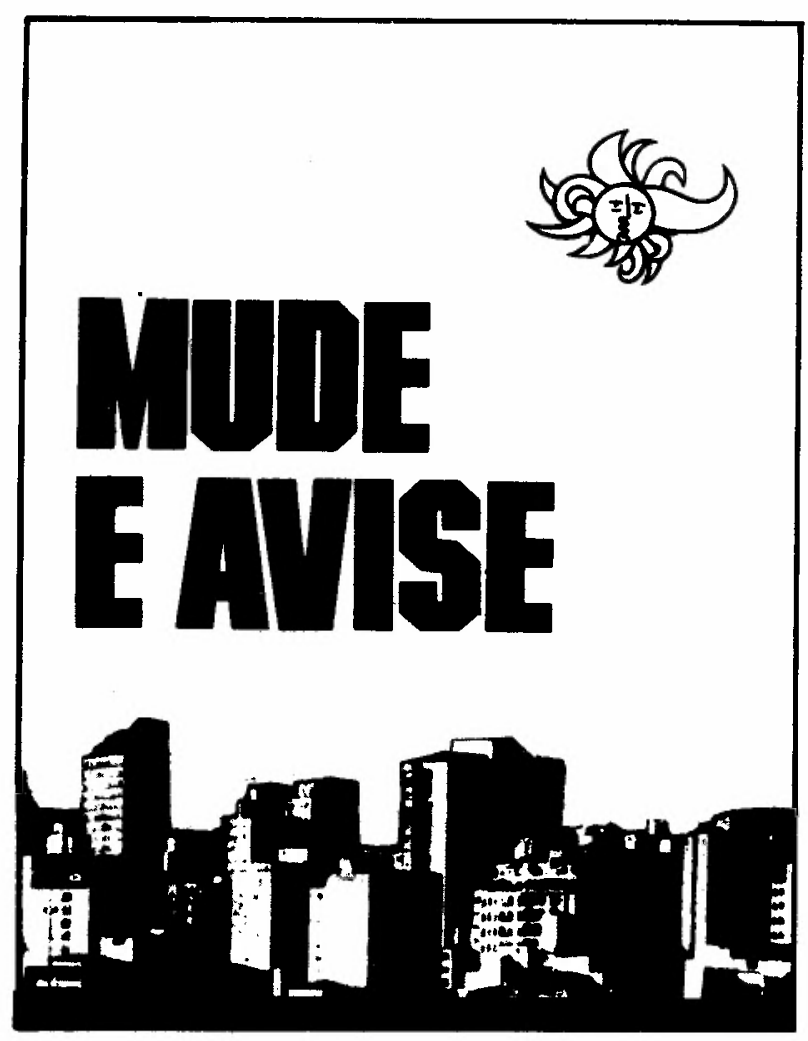

\section{ATENÇATO ASSINANTE}

Mudou-se? Avise-nos.

Aproveite o cartão abaixo para comunicar sua mudança.de endereço. Assim você evita o atraso no recebimento de sua revista.

Por gentileza, mencione o endereço antigo para facilitar nossos serviços. 